\title{
DESIGN OF BUS BODY STRUCTURE BY STATIC ANALYSIS
}

\author{
Sagar S $\mathbf{S}^{1}$, Manjunatha Babu $\mathbf{N ~ S}^{2}$, Nanjunda Reddy A ${ }^{3}$, Mohan Kumar $\mathrm{K}^{4}$ \\ ${ }^{1}$ MTech Student, Mechanical Engineering, DrTTIT, Karnataka, India \\ ${ }^{2,3,4}$ Associate Professor, Mechanical Engineering, DrTTIT, Karnataka, India
}

\begin{abstract}
Transports are the preeminent method of road transportation. The look of the vehicle body depends mainly on driving the execution requirement underneath varying sorts of stacking and managing conditions separated from those of the street conditions. The model investigation moreover, static and modal basic associate analysis of an enunciated urban transport body, was completed with the FEM. In this Project, the bus body was dealt with static analysis with different boundary and loading conditions. Static analysis was carried out for the bus body made up of Titanium, Aluminium and E Glass (Composite Material) to determine the equivalent stress and deformation on considering the self weight of the materials. From the results obtained it can be concluded that the E Glass material was found to be better material compared to other materials. Finally, Self Weight of E Glass was considered to optimize a bus body which may increase its life and efficiency.
\end{abstract}

KeyWords: Static Analysis, E Glass, Equivalent Stress, Deformation, Self Weight

\section{INTRODUCTION}

Automotive chassis is a skeletal frame on which distinctive mechanical parts like motor, tires; rotate assemblies, brakes, coordinating and so forth are shot. The chassis is believed to be the most basic component of an automobile. It is the most noteworthy element that gives quality and security to the vehicle under different conditions. Nature of transport chassis relies on upon the limit of transport. It can be tailormade according to the requirements and can be profited with elements like transverse mounted motor, air suspension and also hostile to move bars.

An all around manufactured transport chassis offers different advantages like high torque from low revs, superior brake performance and more. Transport chassis designed for urban courses contrasts from the one manufactured for rural courses. For transport frameless, chassis development is utilized. In this frame less chassis sort every one of the components is appended to the body. Each of the frame elements is build by the body itself. Because of elimination of long frame it is less expensive and because of less weight most economical too. Just disservice is troublesome in repairing.

The transport body structure must be balanced keeping in mind the end goal to gain the prosperity when the vehicle is running; body must be enough strong in both the condition of supporting ordinary loads and mishap loads. The body contains six fundamental segments; the left edge side, the right edge side, the front edge side, the back edge side, the top casing side and the base edge side. The left and the right side are comparative however the left side is regularly made out of voyager entryways. Of course, the right side has two entryways; the driver entryway and the crisis entryway. The sides are stressed to be essential parts and they should be strong. The static load response of straightforward structures, for instance, uniform bars, plates and tube formed shells, might be procured by comprehending their conditions of motion. The cross zone that is normally used as a piece of making the vehicle body edges is tubular portions (square and rectangular). The $\mathrm{C}$-channel regions are furthermore to give quality and stiffness among the materials utilized for the frames GI tubular and structural steels are commonly utilized. Since the stiffness is the main model for minimizing avoidance and improving quality, studies are directed on the properties of materials. It is found that the young's modulus, which is a measure of stiffness, is high for structural steel. Also the load bearing capacity is higher for structural steel. Subsequently structural steel is chosen as the material for analysis. The behavior of the structure under various load conditions like static, cornering and so on is likewise investigated. The extent of this venture is to give a light weight design which will lessen the weight and also improve the solidness under all the driving conditions. The shear stress following up on the frames is additionally assessed

The design of the inner transport skeleton structure is the premise of different transport developments in the transport enterprises. It contains the structure of tubes with various cross territories are planned inside decided shapes in light of the outline thinking. The vehicle body can be isolated into three areas; the undercarriage and engine, structural body, inside and outside parts. They should easily get through the standard test by household and worldwide association. In this audit, the body and engine are bought from the eminent car brand, for instance, MAN, BENZ, VOLVO, ISUZU, DAEWOO, HINO and so on. The suspension involves two fundamental sorts; the single piece and the three joint mix parts. The single piece frame is used for the medium transport measure with one storey; however the three blend parts are used for the long transport size or two storey 
transports. The second part is the transport body structure. The contains transport body have six primary parts the left and right casing side, the front and back casing side, the top and base edge side. In that the top casing side is at some point called housetop outline side. The base edge side is moreover called floor outline side.

The right and left side are comparable however the left side is ordinarily made out of two voyager entryways. At that point again, the right side has two entryways the driver entryway and crisis entryway. In like manner, the both edge sides are displayed by mirrors and welded with sheet metal. They are concerned to be key parts. They should be strong. The parts should be explanatory tests by in any event reproduction or physical test. Torsion and reshaping tests are generally mimicked by FE analysis. Regardless, the nature of this outline is influenced by the assembling.

The third part, the top casing or the housetop casing is considered as the essential part that is ought to have been a quality part keeping in mind the end goal to be ensured prosperity for the explorers. This part should be satisfactorily strong. It must be bolstered by the total weight from different loads, for instance, inside segments, aeration and cooling systems explorer passing on loads even the air dynamic load. At that point, the back casing and the front casing are generally upheld and joined with the left and right sides and furthermore the housetop outline and the floor outline. These two segments ought to be both strong and radiance style. Accordingly the shape is exceptionally progressed toward becoming arch, slope and extraordinary air dynamic. The present part is additionally consolidated by a significant measure of pieces which is here called trusts.

The cabin and seats have incommodious diagrams that do not provide accomplishment and solace to the driving force. Body orchestrates provide over the highest heat, vibration, whimper, poor solace and security. Wood is getting used as slightly of the amendment of the body to a huge degree. Starting late some acknowledged body manufacturers became increased transport masterminds within the market nonetheless within the time unit a large amount should be done.

\subsection{Literature Survey}

Static \& dynamic anxiety analysis of structural parts of transport frameworks or general mechanical frameworks leads to stresses which were registered exactly when vibration typical modes are portrayed. Dynamic loads that are correctly expected in adaptable multi body dynamic reenactment were used as a piece of stress estimation, along these lines avoiding the dependence on vibration typical modes. Numerical case of transport frameworks, gauges the profitability and exactness of the proposed technique. The hybrid superposition technique is more correct than the mode superposition strategy and more capable than the mode speeding up technique [1]. Structural and Dynamic examination on each structure utilizing 3 materials to select the tactic for the structure was also performed by choosing steel as a material which was supplanted with composite materials like Kevlar and S two Glass Epoxy along with thickness to fade away the heaviness of the structure [2]. In case of medium-sized transport body structure an examination and demonstration using the PC composed (CAD) package UG and limited component (FE) solver ANSYS was carried out to reduce the bus body weight without losing the structure dimensional tolerance by applying the structure of the side of two bodies without and with structure support between the horizontal mid section light emissions side edges while structural streamlining which may reveal that for structural outline enhancement transport body weight diminishes [3]. Focusing on the topology optimization of transport body structure by using Altair-OptiStruct programming which includes static and dynamic analysis also plays an important role in order to improvise weight which depends upon the structure quality before and after optimization [4]. Sometimes fundamental weight for improving the fuel effectiveness, static, dynamic and strong design have to be considered by altering structure column gages with perfect thickness on studying the vehicle execution subjected to various cycles using parameters like rehash, twisting, stress and immovability [5]. Outlining transport complex body part by lessening the amount of parts from the structure and further more thickness towards weight abatement of transport structure may lead to change in mechanical response of car and body styles square measure increasingly which relies upon new models on consideration of comparative and alternative replacing materials for better life and ergonomics of the structures with application of new technical software tools [6]. It can also be understood that design of the transport body depends mainly on driving the performance constraint under different sorts of loading and working circumstances other than those of the street conditions which comprises of shape, solidness reason and quality completed at various working circumstance as per AIS technique [7]. The criticality of the transport body structure depends upon various working conditions, for example, normal static load and Braking loads (speed breakers single wheel street bump, single wheel in), street pot gap and dynamic loads created by: frontal impact which can be depicted through Finite Element modeling finding [8]. The transport bodies which are subjected to outside loads from the street (i.e. traverse a hindrance) may lead to determination of stresses when exposed to certain driving situations and same can be compared with theoretical concept [9]. It has to be very clear that information about reducing the aggregate impact energy transport which is conceivable because of decrease in the mass of the transport, acceleration of free fall or drop tallness of focal point of gravity should meet the final result while determining the aggregate impact energy on rollover transport by subjecting to materialistic conditions [10]. The present work highlights the numerical investigation by applying a static impact load on various conditions of a chosen bus body structure made of different materials which is optimized using relevant analysis tool. 


\section{Methodology.}

- Modeling of Bus Body Structure by using CATIA V5 Software.

- Finite element analysis using Ansys 14.5 for three different chosen materials.

- Static analysis of Titanium, Aluminium and E-Glass.

- Comparing the results of three materials and determination of stresses and deformations.

- Suitable material for bus body is recommended.

Table -1: 55 Seat Capacity Bus Design Parameters

\begin{tabular}{|c|c|c|}
\hline Sl. No & Parameters & Dimensions \\
\hline 1 & Length & $11.66 \mathrm{~m}$ \\
\hline 2 & Width & $2.47 \mathrm{~m}$ \\
\hline 3 & Height & $3.24 \mathrm{~m}$ \\
\hline 4 & Wheel base & $2.16 \mathrm{~m}$ \\
\hline
\end{tabular}

The three Dimensional model was created by using CATIA v5 while Pre-processing were performed on using CAE software ANSYS 14.5 by importing the model from CATIA V5. Meshing and post processing works has been carried out by using the same software tool.

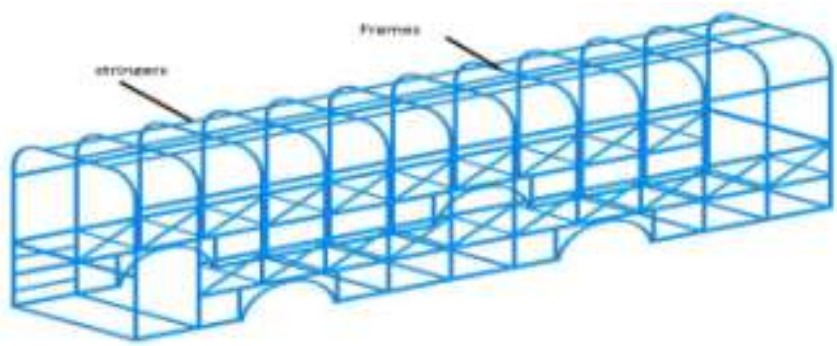

Fig -1: Isometric view of the Bus Body structure

The various views of bus body structure with shape and dimensions lengthwise - widthwise - height and other dimensions are as shown in below figure 2 and 3 .
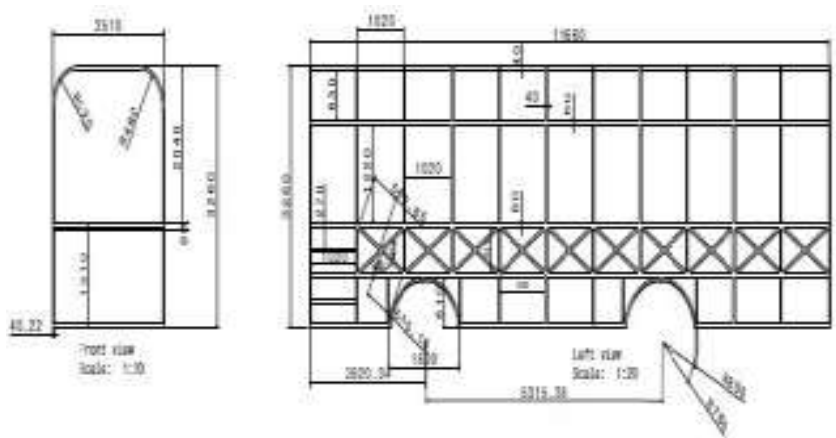

Fig -2: Side view

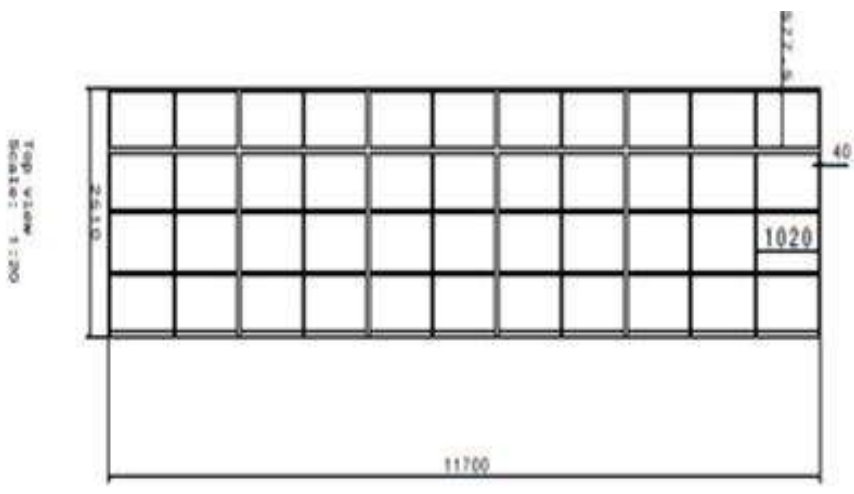

Fig -3: Front view

\subsection{Static Analysis}

The equivalent stress (von-mises stress), maximum and minimum deformations in the structure, stresses and forces in components when subjected to a different loading conditions are determined by static analysis. In this analysis the effect of damping and inertia effects are not caused by loads. The response of the structure changes slowly with respect to time so the steady state loading and response conditions are taken into consideration.

The following steps are the procedure for solving the FE model by using ANSYS 14.5 software. After solving the FE model post processing is carried by using same software to obtain equivalent stress, principal stresses and deformation.

1. Analysis type - Structural.

2. Element type - 3-D Hex dominate.

3. Material properties- As shown in below table 2.

4. Boundary condition- Fixed at the bottom of Bus.

5. Loads- Impact load of $180 \mathrm{~N}$.

6. Solve.

7. Post processing- Stresses and deformations results.

\subsection{Material Properties}

It is necessary to choose an appropriate material and cross section for the structure to withstand the stress developed during the static and dynamic loading conditions. The safety and eco-friendly are the two important characteristics considered in the case of mass transportation vehicles, such as buses which cover significant distances.

- It must ensure light weight.

- It should be able to take heavy load during impact.

- It should provide longer life.

- The material should be easily available at low cost.

- The material used for construction should undergo less deformation during impact loads.

- Fabrication plays an important role in material selection. 
Table -2: The material properties of material used for bus structure.

\begin{tabular}{|c|c|c|c|c|}
\hline $\begin{array}{c}\text { Sl } \\
\text { No }\end{array}$ & Properties & Titanium & Aluminium & E-Glass \\
\hline 1 & $\begin{array}{c}\text { Young's } \\
\text { Modulus }\end{array}$ & $100 \mathrm{Gpa}$ & $70 \mathrm{Gpa}$ & $125 \mathrm{Mpa}$ \\
\hline 2 & $\begin{array}{c}\text { Poisson's } \\
\text { Ratio }\end{array}$ & 0.36 & 0.34 & 0.28 \\
\hline 3 & Density & $4.5 \mathrm{Mg} / \mathrm{m} 3$ & $2.7 \mathrm{Mg} / \mathrm{m} 3$ & $1.8 \mathrm{Mg} / \mathrm{m} 3$ \\
\hline 4 & $\begin{array}{c}\text { Coefficient } \\
\text { of thermal } \\
\text { expansion }\end{array}$ & $9.4 * 10-6 / \mathrm{C}$ & $33 * 10-6 / \mathrm{C}$ & $5 \mu \mathrm{m} / \mathrm{m} \cdot{ }^{\circ} \mathrm{C}$ \\
\hline 5 & $\begin{array}{c}\text { Yield } \\
\text { strength }\end{array}$ & $910 \mathrm{Mpa}$ & $500 \mathrm{Mpa}$ & $125 \mathrm{Mpa}$ \\
\hline
\end{tabular}

\section{Titanium}

Titanium which is a transition material was selected because of its good strength and yield strength of $910 \mathrm{MPa}$. Finite element method model has been prepared using ANSYS 14.5. Meshing 3D model of flat edge specimen includes selection of hex dominate method with 22000 element no and 31540 nodes. The equivalent von-mises stress of $316.82 \mathrm{Mpa}$, maximum principle stress of $524.46 \mathrm{Mpa}$, minimum principal stress of $196.42 \mathrm{Mpa}$ and deformation of $2.8263 \mathrm{~mm}$ was determined by Finite Element Analysis.

\section{Aluminum Material}

Aluminum as an alternate material which is a ductile material chosen for the bus body because of its good strength characterized by yield stress of $500 \mathrm{Mpa}$. The equivalent von-mises stress of $86.75 \mathrm{Mpa}$, maximum principle stress of $158.85 \mathrm{Mpa}$, minimum principal stress of $69.421 \mathrm{Mpa}$ and deformation of $2.3517 \mathrm{~mm}$ were obtained.

\section{E-Glass}

E-GLASS was chosen as an alternate material for the bus body which is a composite material because of its good strength and light weight compared to the above two cases having a yield strength of $125 \mathrm{mpa}$. The equivalent von-mises stress of $28.9 \mathrm{Mpa}$, maximum principal stress of $52.937 \mathrm{Mpa}$, minimum principal stress of $23.145 \mathrm{Mpa}$ and deformation of $0.78398 \mathrm{~mm}$ were determined.

\subsection{Meshing Criteria}

To obtain the accurate results the quality parameters should be maintained. The table below represents the quality parameters to be followed during the analysis.

Table -3: Quality Parameters

\begin{tabular}{|c|c|}
\hline Aspect Ratio & $<5$ \\
\hline Jacobian & $>0.6$ \\
\hline Warpage angle & $<15$ \\
\hline Skew angle & $<60$ \\
\hline
\end{tabular}

a) Aspect Ratio: It is the amount of the simplest to its associating aspect.

b) Jacobian: Jacobians that the live of the deviation of a given component from associate ideally shaped component.

c) Warpage angle: The total by which an element or element stand up to (if there should rise an occasion of solid elements) veers off from being planar.

d) Skew angle: Skew in tries is figured by finding the base edge between the vector from each inside to the keeping mid-side and the vector between the two interfacing mid-sides at every inspiration driving union of the element.

After creating the geometry of the bus body structure, it was imported to ansys software for further analysis. For mesh convergence, the required structure was selected and the size of the elements was varied from course to fine and the deflections produced were observed. It was found that optimum result obtained when the element size set as $5 \mathrm{~mm}$.

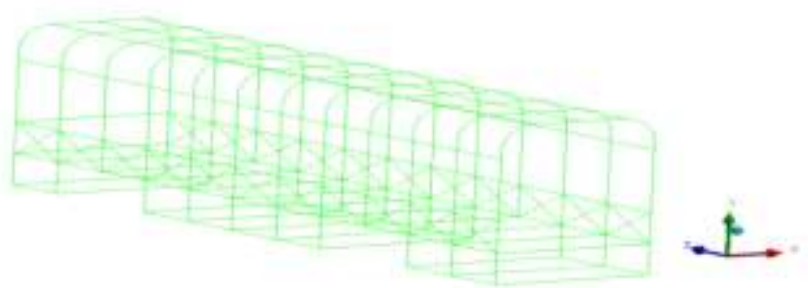

Fig -4: Mesh model of bus body structure after importing from CATIA

The table 4 provides the details of type of element, no of elements and nodes used in FE analysis. The Meshing 3D models of flat edge specimen uses hex dominate method having Quad and Tetra elements. Each element was having 6 degrees of freedom with 22000 element no and 31540 nodes.

Table -4: Meshing criteria

\begin{tabular}{|c|c|}
\hline Mesh method & Tetrahedran/quadrilateral type \\
\hline No of elements & 22000 \\
\hline No of nodes & 31540 \\
\hline
\end{tabular}

\subsection{Boundary Conditions on Bus Body}

The boundary condition used in the analysis is different according to the operating circumstances of the bus. Boundary conditions are applied by fixing the bottom of bus body as shown in Figure 5. During the static loading case the main loads that are considered is impact load of $180 \mathrm{~N}$ which was taken into consideration. 


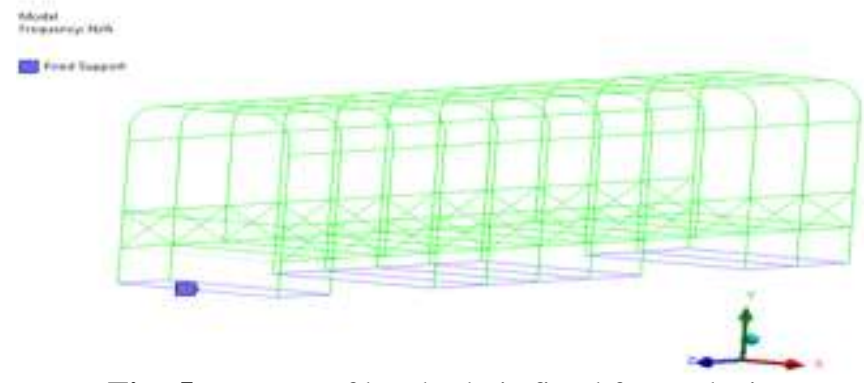

Fig -5: Bottom of bus body is fixed for analysis

The static analysis was carried for 3 different materials to ascertain the results pertaining to the choice of recommendations.

\section{Case 1:}

\begin{tabular}{|c|c|c|c|}
\hline Material & $\begin{array}{c}\text { Young's } \\
\text { modulus }\end{array}$ & $\begin{array}{c}\text { Poisons } \\
\text { ratio }\end{array}$ & $\begin{array}{c}\text { Yield } \\
\text { strength }\end{array}$ \\
\hline Titanium & $100 \mathrm{Gpa}$ & 0.36 & $910 \mathrm{Mpa}$ \\
\hline
\end{tabular}

Von-mises yield criterion recommends that yielding of a material begins when the second deviatory stress invariant influences a critical value. It is part of plasticity theory that applies best to ductile materials, such as some metals. Prior to yield, material response can be assumed to be of a nonlinear elastic, viscoelastic or linear elastic behavior in nature. The figure 6 shows von mises stress distribution on the entire bus body structure. The different color code indicates a different stress concentration at different regions in the model. It is seen that the maximum equivalent stress of $316.82 \mathrm{Mpa}$ for impact load of $180 \mathrm{~N}$ was found in the graphic.

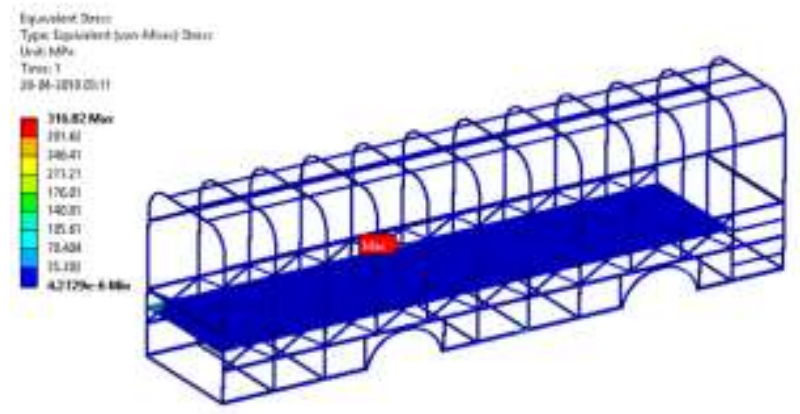

Fig -6: Vonmises stress of a titanium material is $316.82 \mathrm{Mpa}$.

As per the figure 7, According to the theory of maximum principal stress, The failure of a material or component drive occur when the maximum value of principal stress developed in the body exceeds the limiting value of stress, Let us explain the maximum principal stress theory by considering here bus body which is subjected with an external load an Maximum principal stress is $524.46 \mathrm{Mpa}$ for impact load of $180 \mathrm{~N}$.

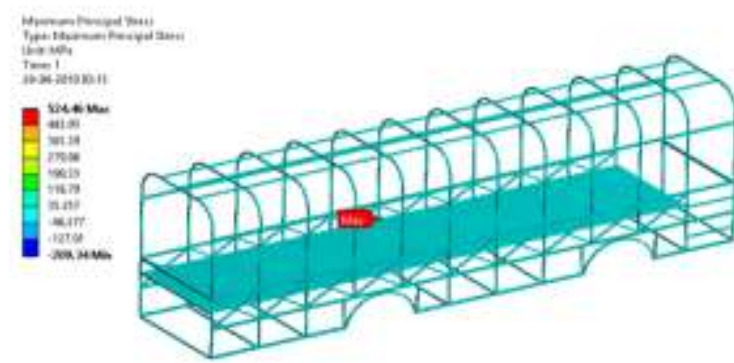

Fig -7: Maximum principal stress of a titanium material is 324.46Mpa.

From Figure 8, According to the theory of minimum principal stress, the failure of a material or component drive will occur when the minimum value of principal stress developed in the body is less than the limiting value of stress. As per the maximum principal stress theory considered, here bus body which is subjected with an external impact load $180 \mathrm{~N}$ results in a Maximum principal stress of $196.42 \mathrm{Mpa}$.

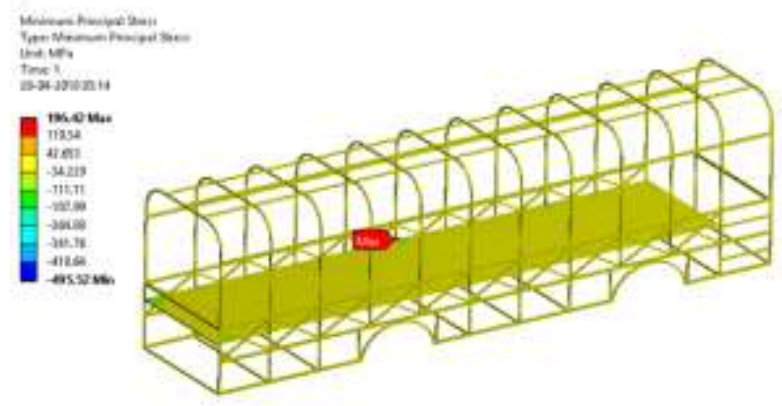

Fig -8: The Minimum principal stress is 196.42 Mpa for titanium material

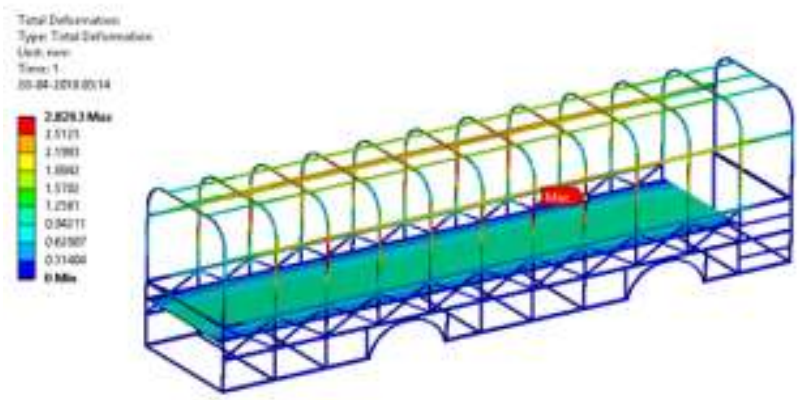

Fig -9: Total deformation is $2.8 \mathrm{~mm}$ for speed for titanium material

From the figure 9 above shows that when the whole bus body structure is subjected to an impact load of $180 \mathrm{~N}$, it yields various deformations at different locations. The color code indicates the minimum deformation which increases gradually and reaches the maximum as shown. The maximum deformation being $2.8263 \mathrm{~mm}$ for the entire body length. 


\section{Case 2:}

\begin{tabular}{|c|c|c|c|}
\hline Material & $\begin{array}{c}\text { Young's } \\
\text { modulus }\end{array}$ & $\begin{array}{c}\text { Poisons } \\
\text { ratio }\end{array}$ & $\begin{array}{c}\text { Yield } \\
\text { strength }\end{array}$ \\
\hline Aluminium & $70 \mathrm{Gpa}$ & 0.34 & $240 \mathrm{Mpa}$ \\
\hline
\end{tabular}

The equivalent stress of $86.766 \mathrm{Mpa}$ can be observed for a impact load of $180 \mathrm{~N}$ from the figure 10 .

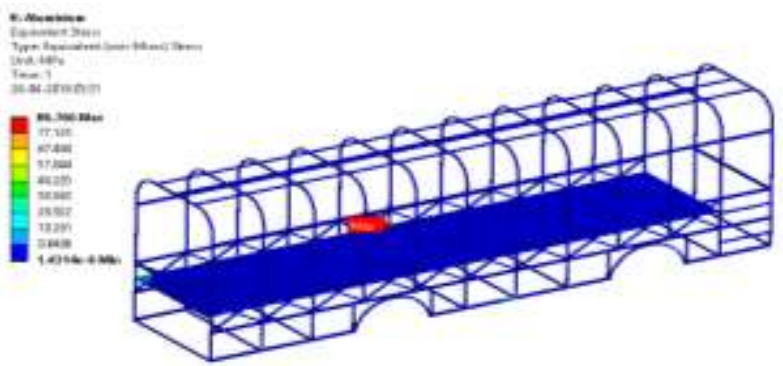

Fig -10: Vonmises stress is $86.766 \mathrm{Mpa}$ for Aluminium Material

In the figure 11 Maximum principal stress is of $158.85 \mathrm{Mpa}$ for impact load of $180 \mathrm{~N}$.

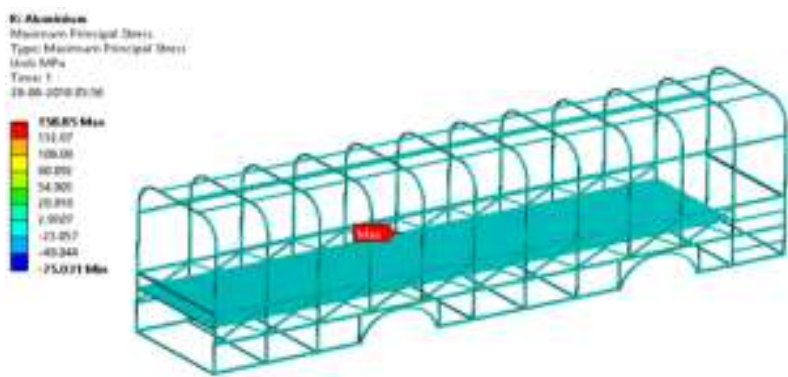

Fig -11: Principal stress is $158.85 \mathrm{Mpa}$ for Aluminium Material.

In the figure 12, The Minimum principal stress is $69.421 \mathrm{mpa}$ for impact load of $180 \mathrm{~N}$.

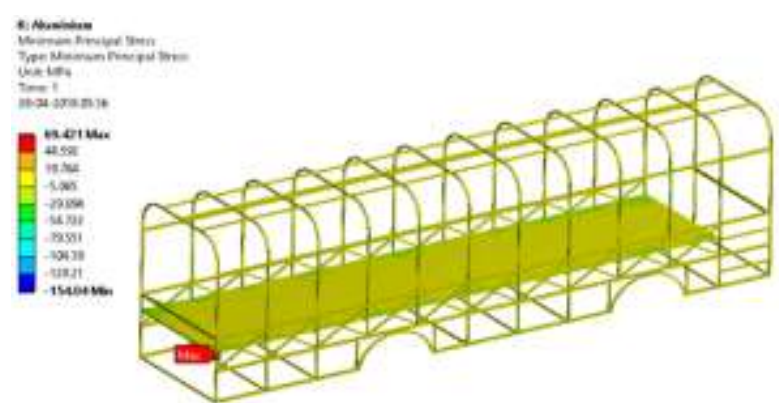

Fig -12: Minimum principal stress of 69.421 Mpa for Aluminium Material

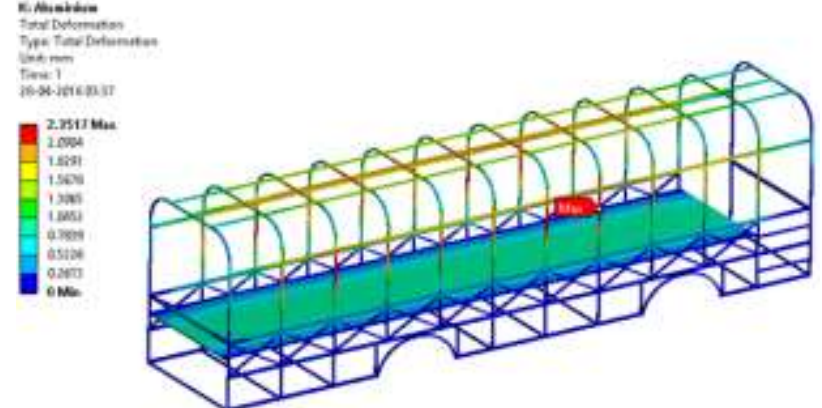

Fig -13: Deformation is $2.8 \mathrm{~mm}$ for Aluminium Material.

From the figure 13, the maximum deformation of the bus body was found to be $2.8263 \mathrm{~mm}$ for the Aluminium material when subjected to impact load of $180 \mathrm{~N}$.

\section{Case 3:}

\begin{tabular}{|c|c|c|c|}
\hline Material & $\begin{array}{c}\text { Young's } \\
\text { modulus }\end{array}$ & $\begin{array}{c}\text { Poisons } \\
\text { ratio }\end{array}$ & $\begin{array}{c}\text { Yield } \\
\text { strength }\end{array}$ \\
\hline E-Glass & $125 \mathrm{Mpa}$ & 0.26 & $125 \mathrm{Mpa}$ \\
\hline
\end{tabular}

From the figure 14 shown below the von Misses yield criterion recommends that yielding of a material begins when the second deviatory stress invariant influences a critical value. It is part of plasticity theory that applies best to ductile materials, related to some metals. Prior to yield, material response can be assumed to be of a nonlinear elastic, viscoelastic or linear elastic behavior and it results in equivalent stress of $28.909 \mathrm{Mpa}$ for an impact load of $180 \mathrm{~N}$.

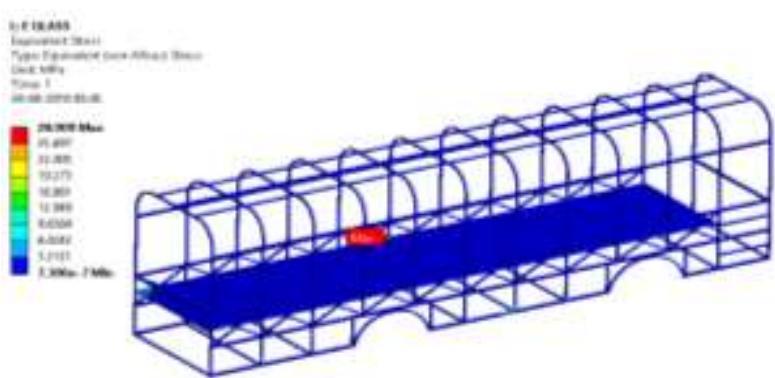

Fig -14: Von-mises stress is 28.909 Mpa for E-Glass

As per the figure 15, According to the theory of maximum principal stress, The failure of a material or component drive occurs when the maximum value of principal stress developed in the body exceeds the limiting value of stress which can understood by considering here a bus body which is subjected to an external load of $180 \mathrm{~N}$ yielding a Maximum principal stress of $52.937 \mathrm{Mpa}$ Maximum principal stress is $52.937 \mathrm{Mpa}$ for impact load of $180 \mathrm{~N}$. 


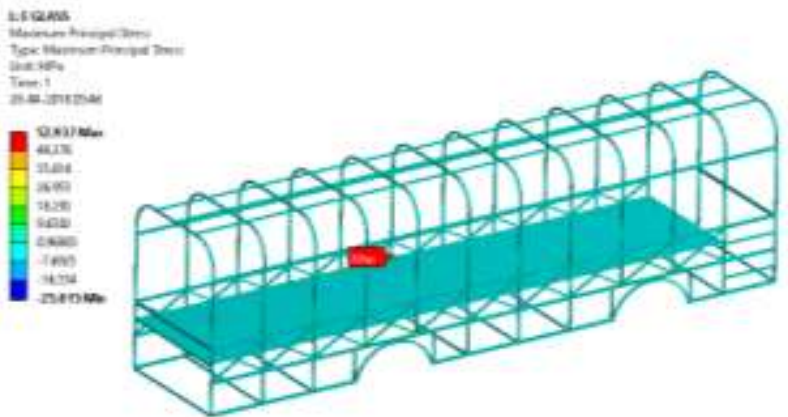

Fig -15: Maximum principal stress is $52.937 \mathrm{MPa}$ for for $\mathrm{E}$ Glass

From the figure 16 shown below, According to the theory of minimum principal stress, the failure of a material or component drive will not occur when the minimum value of principle stress developed in the body is less than the limiting value of stress. This can be understood with respect to the minimum principal stress theory by considering here a bus body which is subjected to an external load of $180 \mathrm{~N}$ resulting in Minimum principal stress of 23.14Mpa.

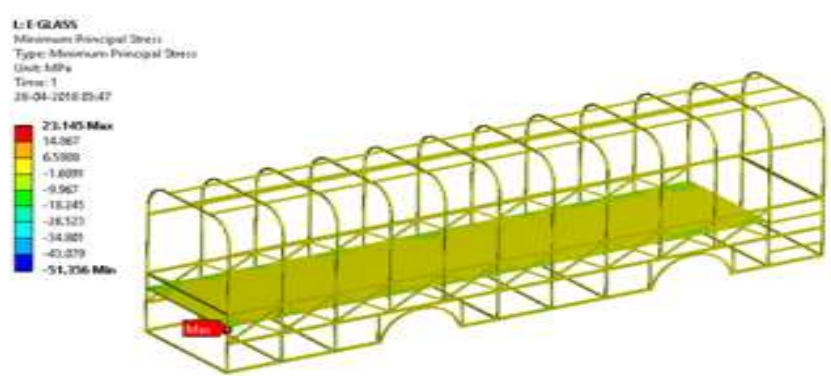

Fig -16: Minimum principal stress is 69.421 for E-Glass

From the figure 3.18 shown, the maximum deformation of the bus body was found to be $2.8263 \mathrm{~mm}$ for the E-Glass material when subjected to impact load of $180 \mathrm{~N}$

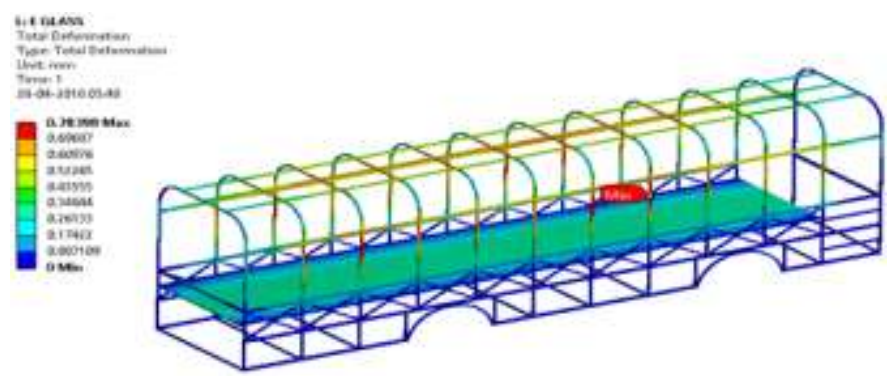

Fig -17: The maximum deformation of the bus body is $2.8263 \mathrm{~mm}$

\section{RESULTS AND DISCUSSIONS}

The static analysis was carried out for a Bus body structure in which the model was discretized into 22000 element and 31540 nodes. This analysis was carried for three different materials Titanium, Aluminium and E-Glass.
The following were the results obtained for the materials when the structure was subjected to static load conditions which were applied with an impact load of $180 \mathrm{~N}$.

Table- 5: Comparison of different stresses and deformation for different materials

\begin{tabular}{|c|c|c|c|c|c|c|}
\hline \multirow[t]{2}{*}{$\begin{array}{l}\text { SI } \\
\text { No }\end{array}$} & \multirow{2}{*}{$\begin{array}{l}\text { Type of } \\
\text { material }\end{array}$} & \multirow{2}{*}{$\begin{array}{c}\text { Weight } \\
\text { in } \\
\mathrm{Kg}\end{array}$} & \multirow{2}{*}{$\begin{array}{l}\text { Von- } \\
\text { mises } \\
\text { stress } \\
\text { Mpa }\end{array}$} & \multicolumn{2}{|c|}{$\begin{array}{c}\text { Principal } \\
\text { stresses } \\
\text { Mpa }\end{array}$} & \multirow{2}{*}{$\begin{array}{c}\text { Deformation } \\
\text { mm }\end{array}$} \\
\hline & & & & Max & Min & \\
\hline 1 & $\mathrm{Ti}$ & 1475.2 & 316.82 & 524.4 & 196.4 & 2.8263 \\
\hline 2 & $\mathrm{Al}$ & 884.49 & 86.75 & 158.8 & 69.42 & 2.3517 \\
\hline 3 & E-Glass & 638.62 & 28.9 & 52.93 & 23.14 & 0.78398 \\
\hline
\end{tabular}

- From this table it is evident that the structure made of titanium material produces a Von-Mises stress of 316.82 Mpa, Aluminium material yields $86.75 \mathrm{MPa}$ and E-Glass produces a stress of $28.9 \mathrm{Mpa}$.

- Similarly the principal stress produced by three materials Titanium, Aluminium and E-Glass structure were 524.46 Mpa, 158.85 Mpa and 52.937 Mpa respectively. The self weights of the bus body structure for different materials used were:

$$
\begin{array}{ll}
\text { Titanium } & -1475.2 \mathrm{Kg} \\
\text { Aluminium } & -884.49 \mathrm{Kg} \\
\text { E-Glass } & -638.62 \mathrm{Kg}
\end{array}
$$

Based the above results it was found that that the E glass material used for bus body structure yields best result as its develops less amount of deformation and stress compared to other materials.

\section{CONCLUSION}

The bus body structure was analyzed for static Impact load of $180 \mathrm{~N}$ with respect to three different materials viz Titanium, Aluminium and E-Glass respectively by using ANSYS 14.5 software. As per the results, it indicates that the structure made of Titanium Material produces more stress and deformation of $316.82 \mathrm{Mpa}$ and $2.8263 \mathrm{~mm}$ respectively while E-Glass material produces less stress and deformation of $28.9 \mathrm{Mpa}$ and $0.78398 \mathrm{~mm}$ respectively. Hence, predication of results shows that a structure made of E-Glass which develops less stress and deformation compared other two materials is recommended for construction of bus body in our project work.

When three different materials are compared with their self weights, E-glass material was found to have a less weight with better mechanical properties. As we know that, the reduction in the weight of the structure will improve the mileage of the vehicle. Hence, this work recommends EGlass for construction of bus body structure as a better material. 


\section{REFERENCES}

[1] H S Kim, T. "Study on the Stiffness Improvement of Bus Structure." SAE paper 931995, 1993.

[2] Dr L.V. Venugopal Rao and Prasanna Priya Chinta "Dynamic Behavior of Three-Wheeler Passenger Vehicle Using Finite Element Method, Rigid Body Modeling and Comparison with Intelligent Design Automation" Journal of Engineering Research and Applications (IJERA), volume no.2, issue no.8, published in 03 November 2015.

[3] F-LAN, J-Chen and J-Lin, "Comparative analysis for bus side structures and lightweight optimization", SAGE Journal, volume 218 and published in October 12004.

[4] Xiu-Chun WU, Wen-Qiang ZHENG, pan ZHOU, "Topology Optimization Design of Bus Body Structure Based on Altair-Optistruct", International Conference on Mechanics and Civil Engineering. The authors Published by Atlantis Press in 2014.

[5] R. Jaina, P. Tandona, M. Vasantha Kumar, "Optimization methodology for beam gauges of the bus body for weight reduction", Applied and Computational Mechanics volume 8 (2014) 47 -62, Received 13 November 2013 and revised from 26 June 2014.

[6] P. Chinta, and L.V. Venugopal Rao, "A New Design and Analysis of Bus Body Structure", IOSR Journal of Mechanical and Civil Engineering, Volume 11, Issue 5 Ver. I, Published in the year Sep- Oct. 2014.

[7] Rajesh S.Rayakar, "design and analysis of bus body superstructure", International Journal for Research in Applied Science and Engineering Technology (IJRAS), Vol. 2 Issue VII, ISSN: 2321-9653, published in July 2014.

[8] D.Purushottam Reddy , S.Sardar ali , D.Srikanth , JV.Mohanachari, "Design And Analysis Of Bus Body Superstructure", IJRDO-Journal of Mechanical and Civil Engineering, Volume-2 ISSN: 2456-1479, published in the year Sep 16-17-2015.

[9] Mahesh Haldankar, A. M. Shirahatti, "Finite Element Analysis and Optimization of Commercial Bus Body Structure", International Journal of Engineering and Technical Research (IJETR) ISSN: 2321-0869, Volume2, Issue-12, December 2014.

[10]B.Y. Kalmikov, N.A. Ovchinnikov, I.Y. Visotski Kalmikov A, ARPN Journal of Engineering and Applied Sciences VOL. 10, NO. 8, MAY 2015 ISSN 1819-6608.

\section{BIOGRAPHIES}

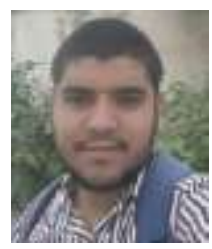

${ }^{1}$ Received his B.E degree in Mechanical Engineering from Dr TTIT under VTU in 2016 and Pursuing his MTech (Machine Design) at Dr TTIT under VTU, Belgaum.

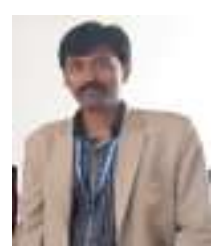

${ }^{2}$ Received his MTech degree in Machine Design from SJCIT under VTU in 2009 and Pursuing his $\mathrm{PhD}$ (Composite Materials) under VTU, Belgaum.

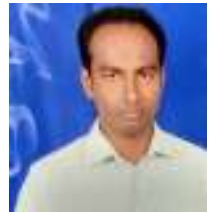

${ }^{3}$ Received his B.E degree in Mechanical Engineering from AIT in 2008 and MTech (Machine Design) from NCET under VTU, Belgaum in 2013.

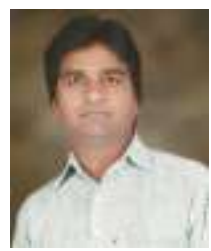

${ }^{4}$ Received his MTech degree in Machine Design from SJCIT under VTU in 2009 and Pursuing his $\mathrm{PhD}$ (Composite Materials) under VIT, Vellore. 